\title{
NUMERICAL INVESTIGATION OF THE INFLUENCE OF PUNCH TIP RADIUS AND INTERPOLATOR TYPE IN MULTI-POINT FORMING
}

\author{
Abdul Kareem Jalil Kadhim \\ drkreem959@yahoo.com \\ Ragad Aziz Neama \\ RagadAziz87@gmail .com \\ University of Babylon, College of Engineering, Mechanical Eng.Dept.
}

\begin{abstract}
Multi-point forming (MPF) is a new flexible forming technology in which the fixed shape of conventional dies is replaced by a pair of opposed matrices of movable punch elements called "punch group".By using multi-point die a variety of three dimensional sheet parts of different shapes can be produced. However due to the discrete contacts between the work piece and punches the dimple defects occurred. In this paper, B-spline technique was used to represent the profile of the final product shape by adjusting the punch height of reconfigurable die. Finite element code (ANSYS 11) was used to simulate the MPF process and to investigate the influence of punch tip radius the interpolator type on the stress distribution, thickness variation and dimpling defect. The simulation results show that the large tip radius and $(4 \mathrm{~mm})$ rubber interpolator have a great effect in reducing the stress concentration, thickness variation and also prevent the dimpling defect.
\end{abstract}

KEYWORDS: multi point forming, B-spline, interpolators, punch tip, numerical simulation.

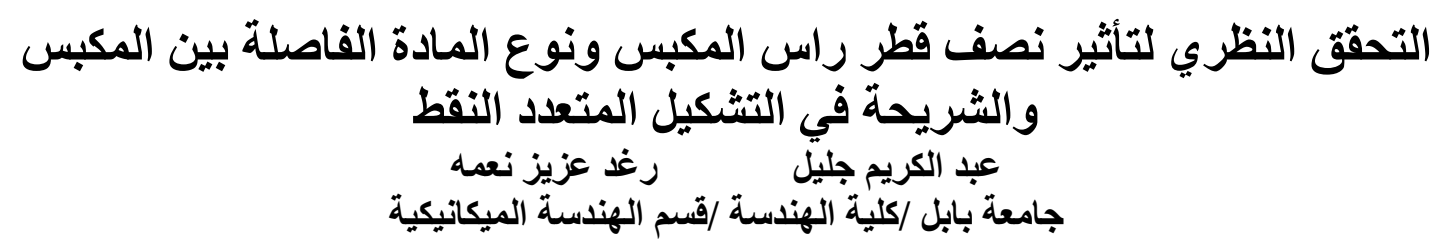

الخلاصة

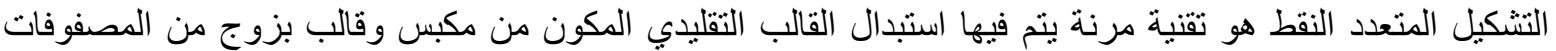

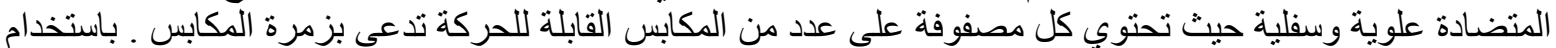

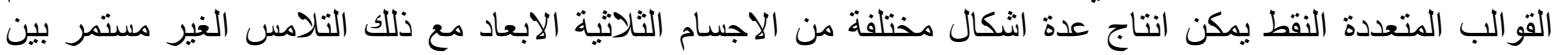

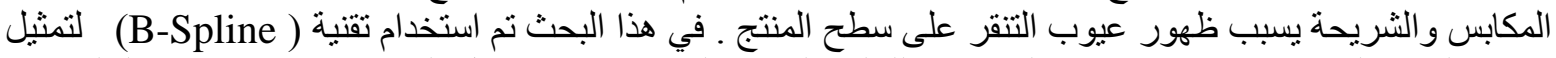

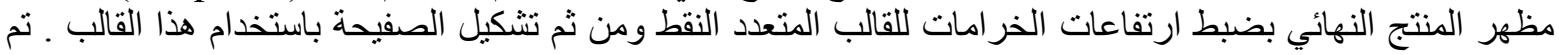

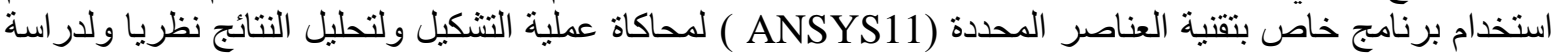

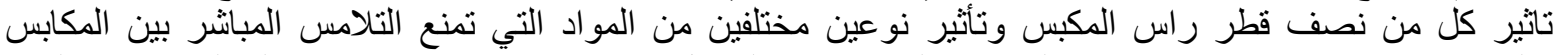

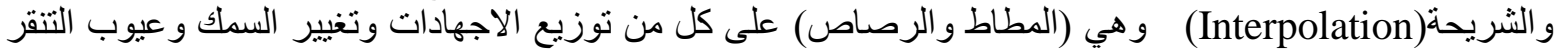

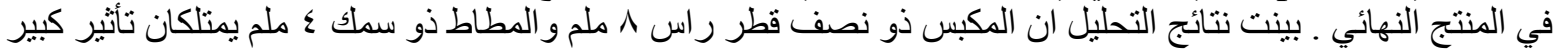

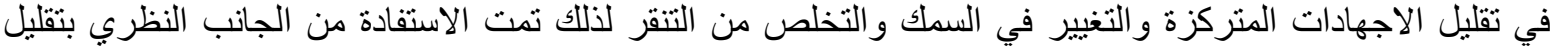

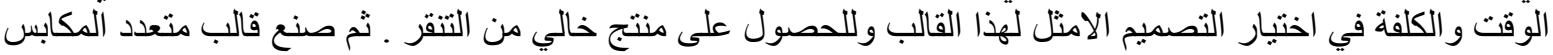

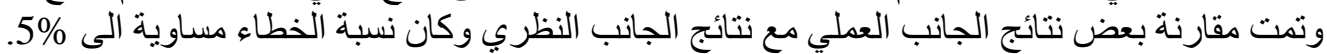




\section{INTRODUCTION}

Traditionally in sheet metal forming, fixed shape matched tool is used to form the part shape. The die which is designed according to the specific shape and manufactured as a single piece is applied to accomplish the sheet metal forming in its cavity. Usually, the die is invariable, thus different dies are required to form different parts, and several sets of dies are needed for the product which is hardly to form in single forming. The main problem of this forming method is that it is extremely expensive to design these complex dies, especially for the small lot size production, because of the development time and the manufacturing costs. For this reason, the possible alternative forming method, which can reduce production costs named multi-point forming process (MPF), has been proposed. Multi-point forming (MPF) is an advanced flexible manufacturing technique rapidly developed for the various three dimensional sheet metal forming demands in recent years. The substance of multi-point forming is replacing the conventional solid dies by a set of discrete punches called "punch group", as shown in Figure(1) [Wang 2010].

[Li et al 2002 ] developed an MPF press with flexible blank holder to manufacture complex sheet metal parts with out wrinkling and tearing defect. [Ming-Zhe 2006] described the overal structure of the digitized die forming (DDF) system and the methods of design and control of digitized die shape,the detailed steps of die shape correction for spring back and forming process simulation are explained. [Zhang et al 2007] investigated the performance of a multi-pin die with pins in cicular array and an adjustable blank holder.This die is suitable to form work-pieces with rotational symmitery. [Cekan et al 2008] performed the finite element simulation of the sheet metal forming to investigate the influence of the pins network type on the deformation process in reconfigurable (MPF) with fixed configuration. [Tan 2009] introduced dynamic explicit finite element software to simulate the MPF of titaniom alloy retiary sheet $(152 * 125) \mathrm{mm}^{2}$ and $0.5 \mathrm{~mm}$ thickness with $30 * 30$ square holl and titanium alloy sheet metal $(152 * 152) \mathrm{mm}^{2}$ and thickness $0.5 \mathrm{~mm}$. [Seong-chan 2010]designed and fabricated a $2000 \mathrm{KN}$ flexible forming machine for forming of thick curved plate used for shipbulding industry. [Shaohui 2010] discussed the influence of the MPSD geometry on the surface quality and the shape accuracy of MPSF parts through analyzing dimple and the shape error after deformation.This paper foucused on studing the effect of interpolator type and thickness also the punch tip radius on MPF process in term stress distribution,thickness variation, and dimpling suppresion.

\section{PRINCIPLE OF MPF}

In MPF,the conventional stamping matched die are replaced by apair of opposed matrices of punch elements with hemispheric end,and the continous surface of conventional die is approximated by the envelope surface of punch matrix.Adjusting the height of each punch element, a multi-point die (MPD)is generated.The spherical tips of punch elements in MPD describe a discrete 3 D surface, and sheet metal parts with the same 3D geometry can be formed by apair of matched MPD .

\section{Construction Of Multi Point Die Shape}

The shape of MPD ,namely the surface of the punch matrix, depends up on the heights of the punches elements in punch matrix,that is mean all the surface point's coordinate must be mesured theoritically.In this paper the general form of curve in two dimension and surface in three dimension is described by open uniform $B$-spline with $(n=k=5)$ with the aid of MATLAB program

$\mathrm{P}(\mathrm{u})=\sum_{\mathrm{i}=0}^{\mathrm{n}} \mathrm{P}_{\mathrm{i}} \mathrm{N}_{\mathrm{i}, \mathrm{k}}(\mathrm{u})$

where $P_{i}$ is a control point, $i$ is the index of the control points, $k$ is the number of the control points that control a segment, $\left(\mathrm{N}_{\mathrm{i}, \mathrm{k}}\right)$ is the b-spline's basis function, and the range of parametric variable (u) must be : $0 \leq \mathrm{u} \leq \mathrm{n}-\mathrm{k}+2$. There are two mathematical definitions of B-spline's basis functions: 


$$
\text { 1-When } \mathrm{k}=1: \mathrm{N}_{\mathrm{i}, 1}(\mathrm{u})=\left\{\begin{array}{cc}
1 & \text { if } \mathrm{t}_{\mathrm{i}} \leq \mathrm{u}<\mathrm{t}_{\mathrm{i}+1} \\
0 & \text { otherwise }
\end{array}\right.
$$

2-When $k>1: N_{i, k}(u)=\left(\frac{\left(u-t_{i}\right)}{\left(t_{i+k-1}-t_{i}\right)}\right) N_{i, k-1}(u)+\frac{\left(t_{i+k}-u\right)}{\left(t_{i+k}-t_{i+1}\right)} N_{i+1, k-1}(u)$

Where $\left(\mathrm{t}_{\mathrm{i}}\right)$ is the knot value .

B-spline curve consists of segments. The join point between these segments are called knots, and play a fundamental role in the understanding of this kind of curve. In the cubic case $(\mathrm{m}=3)$, there are $n+4$ knot values and in the general case $(n+m+1)$, which are commonly stored in a knot vector. The knot vector is used to specify values in the evaluation interval where the curve changes segment. The knot vector for the open-uniform B-spline curve requires the following general condition: $t_{i+1} \geq t_{i}$. One of the forms of the open-uniform knot vector is as follows (Shaohui etal.2010)

$\left.\begin{array}{ll}\mathrm{t}_{\mathrm{i}}=0 & \text { if } \mathrm{i}<\mathrm{k} \\ \mathrm{t}_{\mathrm{i}}=\mathrm{i}-\mathrm{k}+1 & \text { if } \mathrm{k} \leq \mathrm{i} \leq \mathrm{n} \\ \mathrm{t}_{\mathrm{i}}=\mathrm{n}-\mathrm{k}+2 & \text { if } \mathrm{i}>\mathrm{n}\end{array}\right\}$ Where $0 \leq \mathrm{i} \leq \mathrm{n}+\mathrm{k}$

In the derivative of the open-uniform B-spline Basis functions with $(k=n=5)$, the open-uniform Bspline basis function is determined by the general equation (3). While $(\mathrm{k})$ is the equation order and $(\mathrm{k}-1)$ is the equation degree, $\mathrm{T}=\mathrm{knot}$ vector and knot value symbolized by $\left(\mathrm{t}_{\mathrm{i}}\right)$.

- The number of control points $=\mathrm{n}+1=6$ points.

- The number of segments $=\mathrm{n}-\mathrm{k}+2=2$ segments.

- The number of control point per segment $=\mathrm{k}=5$.

- The number of knots in the knot vector equal to $n+k+1=11$ knots.

The range of parametric variable $(\mathrm{u})$ must be $: 0 \leq \mathrm{u} \leq 2$. The knot vector of the open uniform $\mathrm{B}$-spline is: $\mathrm{T}=\left[\mathrm{t}_{0}, \mathrm{t}_{1}, \mathrm{t}_{2}, \mathrm{t}_{3}, \mathrm{t}_{4}, \mathrm{t}_{5}, \mathrm{t}_{6}, \mathrm{t}_{7}, \mathrm{t}_{8}, \mathrm{t}_{9}, \mathrm{t}_{10}\right]=[0,0,0,0,0,1,2,2,2,2,2]$. The basis functions at $\mathrm{k}=1$ are given by:

$\mathrm{N}_{0,1}(\mathrm{u})=\left\{\begin{array}{l}1 \text { for } t_{0} \leq \mathrm{u}<\mathrm{t}_{1} \\ 0 \text { otherwise }\end{array}, \mathrm{N}_{1,1}(\mathrm{u})=\left\{\begin{array}{l}1 \text { for } t_{1} \leq \mathrm{u}<\mathrm{t}_{2} \\ 0 \text { otherwise }\end{array}\right.\right.$

$N_{2,1}(u)= \begin{cases}1 & \text { for } t_{2} \leq u<t_{3} \\ 0 & \text { otherwise }\end{cases}$

$N_{3,1}(u)=\left\{\begin{array}{l}1 \text { for } t_{3} \leq u<t_{4} \\ 0 \text { otherwise }\end{array}\right.$,

$\mathrm{N}_{4,1}(\mathrm{u})=\left\{\begin{array}{c}1 \text { for } \mathrm{t}_{4} \leq \mathrm{u}<\mathrm{t}_{5} \\ 0 \text { otherwise }\end{array}\right.$,

$\mathrm{N}_{5,1}(\mathrm{u})=\left\{\begin{array}{c}1 \text { for } t_{5} \leq \mathrm{u}<\mathrm{t}_{6} \\ 0 \text { otherwise }\end{array}\right.$

And $N_{6,1}(u)=\left\{\begin{array}{l}1 \text { for } t_{6} \leq u<t_{7} \\ 0 \text { otherwise }\end{array}\right.$ 
From the equation (2) the value of basis function are:

$\mathrm{N}_{0,1}(\mathrm{u})=\mathrm{N}_{1,1}(\mathrm{u})=\mathrm{N}_{2,1}(\mathrm{u})=\mathrm{N}_{3,1}(\mathrm{u})=0$ because $0 \leq \mathrm{u}<0$, and $\mathrm{N}_{6,1}(\mathrm{u})=\mathrm{N}_{7,1}(\mathrm{u})=\mathrm{N}_{8,1}(\mathrm{u})=\mathrm{N}_{9,1}(\mathrm{u})=0$ because $2 \leq \mathrm{u}<2$. but $\mathrm{N}_{4,1}(\mathrm{u})=1$ because $0 \leq \mathrm{u}<1$, and $\mathrm{N}_{5,1}(\mathrm{u})=1$ because $1 \leq \mathrm{u}<2$.

To simplify derivation, it s easily to make a table includes all variables which are required in the equation (3) to reach the final equations. When $\mathrm{k}=2$

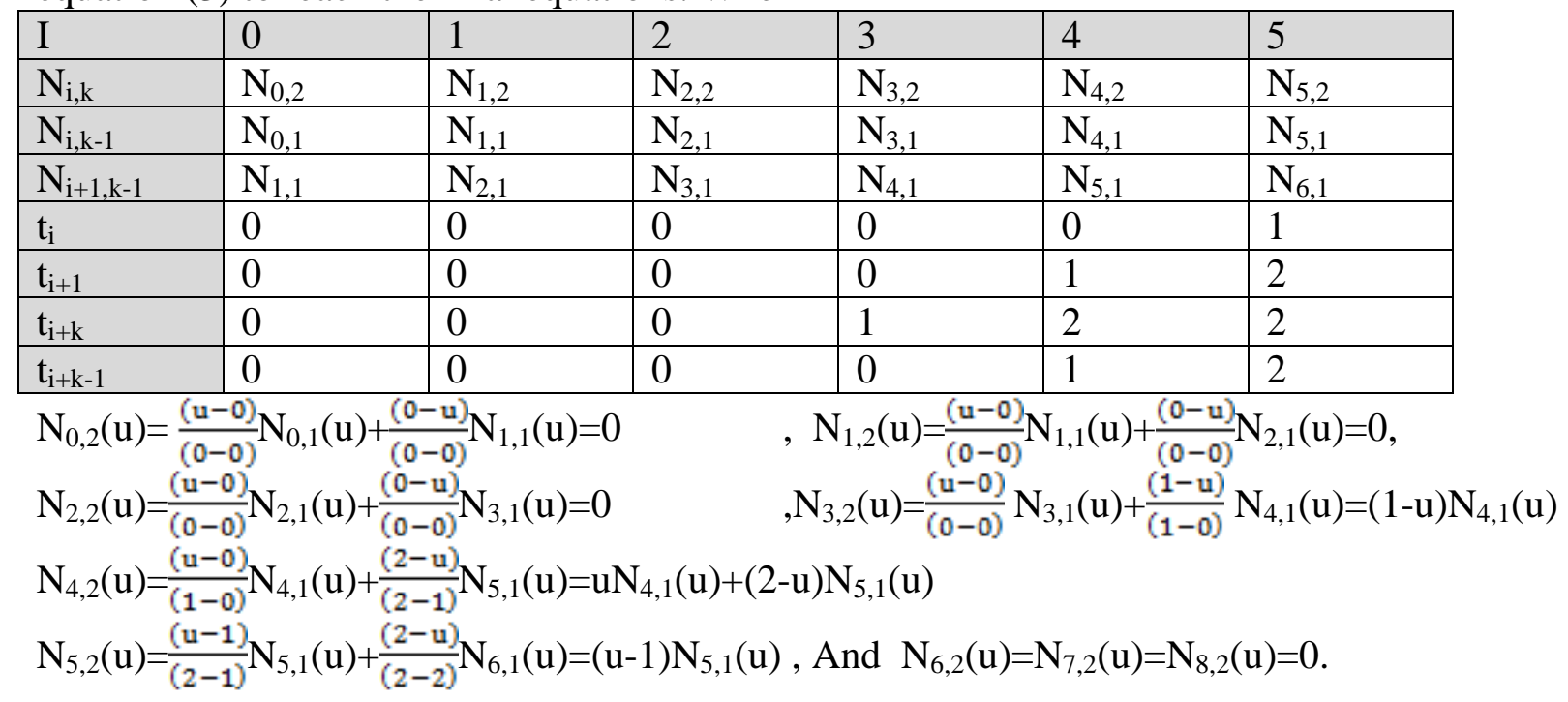

Unlike the mathematical rules and during the calculation of B-spline surfaces any quantity divided by zero is equal to zero rather than infinity [Michael 1996]. When $\mathrm{k}=3$

\begin{tabular}{|c|c|c|c|c|c|c|}
\hline I & 0 & 1 & 2 & 3 & 4 & 5 \\
\hline $\mathrm{N}_{\mathrm{i}, \mathrm{k}}$ & $\mathrm{N}_{0,3}$ & $\mathrm{~N}_{1,3}$ & $\mathrm{~N}_{2,3}$ & $\mathrm{~N}_{3,3}$ & $\mathrm{~N}_{4,3}$ & $\mathrm{~N}_{5,3}$ \\
\hline $\mathrm{N}_{\mathrm{i}, \mathrm{k}-1}$ & $\mathrm{~N}_{0,2}$ & $\mathrm{~N}_{1,2}$ & $\mathrm{~N}_{2,2}$ & $\mathrm{~N}_{3,2}$ & $\mathrm{~N}_{4,2}$ & $\mathrm{~N}_{5,2}$ \\
\hline $\mathrm{N}_{\mathrm{i}+1, \mathrm{k}-1}$ & $\mathbf{N}_{1,2}$ & $\mathrm{~N}_{2,2}$ & $\mathrm{~N}_{3,2}$ & $\mathrm{~N}_{4,2}$ & $\mathrm{~N}_{5,2}$ & $\mathrm{~N}_{6,2}$ \\
\hline $\mathrm{t}_{\mathrm{i}}$ & 0 & 0 & 0 & 0 & 0 & 1 \\
\hline$t_{i+1}$ & 0 & 0 & 0 & 0 & 1 & 2 \\
\hline$t_{i+k}$ & 0 & 0 & 1 & 2 & 2 & 2 \\
\hline $\mathrm{t}_{\mathrm{i}+\mathrm{k}-1}$ & 0 & 0 & 0 & 1 & 2 & 2 \\
\hline \multicolumn{7}{|c|}{$\begin{array}{l}\mathrm{N}_{0,3}(\mathrm{u})=\frac{(\mathrm{u}-0)}{(0-0)} \mathrm{N}_{0,2}(\mathrm{u})+\frac{(0-\mathrm{u})}{(0-0)} \mathrm{N}_{1,2}(\mathrm{u})=0 \quad, \mathrm{~N}_{1,3}(\mathrm{u})=\frac{(\mathrm{u}-0)}{(0-0)} \mathrm{N}_{1,2}(\mathrm{u})+\frac{(0-\mathrm{u})}{(0-0)} \mathrm{N}_{2,2}(\mathrm{u})=0 \\
\mathrm{~N}_{2,3}(\mathrm{u})=\frac{(\mathrm{u}-0)}{(0-0)} \mathrm{N}_{2,2}(\mathrm{u})+\frac{(1-\mathrm{u})}{(1-0)} \mathrm{N}_{3,2}(\mathrm{u})=(1-\mathrm{u}) \mathrm{N}_{3,2}(\mathrm{u}) \\
\mathrm{N}_{3,3}(\mathrm{u})=\frac{(\mathrm{u}-0)}{(1-0)} \mathrm{N}_{3,2}(\mathrm{u})+\frac{(2-\mathrm{u})}{(2-0)} \mathrm{N}_{4,2}(\mathrm{u})=\left[(\mathrm{u}) \mathrm{N}_{3,2}(\mathrm{u})+\frac{(2-\mathrm{u})}{2} \mathrm{~N}_{4,2}(\mathrm{u})\right] \\
\mathrm{N}_{4,3}(\mathrm{u})=\frac{(\mathrm{u}-0)}{(2-0)} \mathrm{N}_{4,2}(\mathrm{u})+\frac{(2-\mathrm{u})}{(2-1)} \mathrm{N}_{5,2}(\mathrm{u})=\frac{\mathrm{u}}{2} \mathrm{~N}_{4,2}(\mathrm{u})+\frac{(2-\mathrm{u})}{(2-1)} \mathrm{N}_{5,2}(\mathrm{u})\end{array}$} \\
\hline
\end{tabular}

When $\mathrm{k}=4$

\begin{tabular}{|c|c|c|c|c|c|c|}
\hline I & 0 & 1 & 2 & 3 & 4 & 5 \\
\hline $\mathrm{N}_{\mathrm{i}, \mathrm{k}}$ & $\mathrm{N}_{0,4}$ & $\mathbf{N}_{1,4}$ & $\mathrm{~N}_{2,4}$ & $\mathrm{~N}_{3,4}$ & $\mathrm{~N}_{4,4}$ & $\mathrm{~N}_{5,4}$ \\
\hline $\mathrm{N}_{\mathrm{i}, \mathrm{k}-1}$ & $\mathrm{~N}_{0,3}$ & $\mathrm{~N}_{1,3}$ & $\mathrm{~N}_{2,3}$ & $\mathrm{~N}_{3,3}$ & $\mathrm{~N}_{4,3}$ & $\mathrm{~N}_{5,3}$ \\
\hline $\mathrm{N}_{\mathrm{i}+1, \mathrm{k}-1}$ & $\mathbf{N}_{1,3}$ & $\mathbf{N}_{2,3}$ & $\mathrm{~N}_{3,3}$ & $\mathrm{~N}_{4,3}$ & $\mathrm{~N}_{5,3}$ & $\mathrm{~N}_{6,3}$ \\
\hline $\mathrm{t}_{\mathrm{i}}$ & 0 & 0 & 0 & 0 & 0 & 1 \\
\hline$t_{i+1}$ & 0 & 0 & 0 & 0 & 1 & 2 \\
\hline$t_{i+k}$ & 0 & 1 & 2 & 2 & 2 & 2 \\
\hline $\mathrm{t}_{\mathrm{i}+\mathrm{k}-1}$ & 0 & 0 & 1 & 2 & 2 & 2 \\
\hline
\end{tabular}


$\mathrm{N}_{2,4}(\mathrm{u})=\frac{(\mathrm{u}-0)}{(1-0)} \mathrm{N}_{2,3}(\mathrm{u})+\frac{(2-\mathrm{u})}{(2-0)} \mathrm{N}_{3,3}(\mathrm{u})=\mathrm{uN}_{2,3}(\mathrm{u})+\frac{(2-\mathrm{u})}{2} \mathrm{~N}_{3,3}(\mathrm{u})$,

$\mathrm{N}_{3,4}(\mathrm{u})=\frac{(\mathrm{u}-0)}{(2-0)} \mathrm{N}_{3,3}(\mathrm{u})+\frac{(2-\mathrm{u})}{(2-0)} \mathrm{N}_{4,3}(\mathrm{u})=\frac{\mathrm{u}}{2} \mathrm{~N}_{3,3}(\mathrm{u})+\frac{(2-\mathrm{u})}{2} \mathrm{~N}_{4,3}(\mathrm{u})$,

$\mathrm{N}_{4,4}(\mathrm{u})=\frac{(\mathrm{u}-0)}{(2-0)} \mathrm{N}_{4,3}(\mathrm{u})+\frac{(2-\mathrm{u})}{(2-1)} \mathrm{N}_{5,3}(\mathrm{u})=\frac{\mathrm{u}}{2} \mathrm{~N}_{4,3}(\mathrm{u})+(2-\mathrm{u}) \mathrm{N}_{5,3}(\mathrm{u})$,

$\mathrm{N}_{5,4}(\mathrm{u})=\frac{(\mathrm{u}-1)}{(2-1)} \mathrm{N}_{5,3}(\mathrm{u})+\frac{(2-\mathrm{u})}{(2-2)} \mathrm{N}_{6,3}(\mathrm{u})=(\mathrm{u}-1) \mathrm{N}_{5,3}(\mathrm{u})$, And $\mathrm{N}_{6,4}(\mathrm{u})=0$

And finally for $\mathrm{k}=5$

\begin{tabular}{|l|l|l|l|l|l|l|}
\hline $\mathrm{I}$ & 0 & 1 & 2 & 3 & 4 & 5 \\
\hline $\mathrm{N}_{\mathrm{i}, \mathrm{k}}$ & $\mathrm{N}_{0,5}$ & $\mathrm{~N}_{1,5}$ & $\mathrm{~N}_{2,5}$ & $\mathrm{~N}_{3,5}$ & $\mathrm{~N}_{4,5}$ & $\mathrm{~N}_{5,5}$ \\
\hline $\mathrm{N}_{\mathrm{i}, \mathrm{k}-1}$ & $\mathrm{~N}_{0,4}$ & $\mathrm{~N}_{1,4}$ & $\mathrm{~N}_{2,4}$ & $\mathrm{~N}_{3,4}$ & $\mathrm{~N}_{4,4}$ & $\mathrm{~N}_{5,4}$ \\
\hline $\mathrm{N}_{\mathrm{i}+1, \mathrm{k}-1}$ & $\mathrm{~N}_{1,4}$ & $\mathrm{~N}_{2,4}$ & $\mathrm{~N}_{3,4}$ & $\mathrm{~N}_{4,4}$ & $\mathrm{~N}_{5,4}$ & $\mathrm{~N}_{6,4}$ \\
\hline $\mathrm{t}_{\mathrm{i}}$ & 0 & 0 & 0 & 0 & 0 & 1 \\
\hline $\mathrm{t}_{\mathrm{i}+1}$ & 0 & 0 & 0 & 0 & 1 & 2 \\
\hline $\mathrm{t}_{\mathrm{i}+\mathrm{k}}$ & 1 & 2 & 2 & 2 & 2 & 2 \\
\hline $\mathrm{t}_{\mathrm{i}+\mathrm{k}-1}$ & 0 & 1 & 2 & 2 & 2 & 2 \\
\hline
\end{tabular}

$\mathrm{N}_{0,5}(\mathrm{u})=\frac{(\mathrm{u}-0)}{(0-0)} \mathrm{N}_{0,4}(\mathrm{u})+\frac{(1-\mathrm{u})}{(1-0)} \mathrm{N}_{1,4}(\mathrm{u})=(1-\mathrm{u}) \mathrm{N}_{1,4}(\mathrm{u})$

$\mathrm{N}_{1,5}(\mathrm{u})=\frac{(\mathrm{u}-0)}{(1-0)} \mathrm{N}_{1,4}(\mathrm{u})+\frac{(2-\mathrm{u})}{(2-0)} \mathrm{N}_{2,4}(\mathrm{u})=(\mathrm{u}) \mathrm{N}_{1,4}(\mathrm{u})+\frac{(2-\mathrm{u})}{2} \mathrm{~N}_{2,4}(\mathrm{u})$

$\mathrm{N}_{2,5}(\mathrm{u})=\frac{(\mathrm{u}-0)}{(2-0)} \mathrm{N}_{2,4}(\mathrm{u})+\frac{(2-\mathrm{u})}{2} \mathrm{~N}_{3,4}(\mathrm{u})=\frac{\mathrm{u}}{2} \mathrm{~N}_{2,4}(\mathrm{u})+\frac{(2-\mathrm{u})}{2} \mathrm{~N}_{3,4}(\mathrm{u})$

$\mathrm{N}_{3,5}(\mathrm{u})=\frac{(\mathrm{u}-0)}{(2-0)} \mathrm{N}_{3,4}(\mathrm{u})+\frac{(2-\mathrm{u})}{(2-0)} \mathrm{N}_{4,4}(\mathrm{u})=\frac{\mathrm{u}}{2} \mathrm{~N}_{3,4}(\mathrm{u})+\frac{(2-\mathrm{u})}{2} \mathrm{~N}_{4,4}(\mathrm{u})$

$\mathrm{N}_{4,5}(\mathrm{u})=\frac{(\mathrm{u}-0)}{(2-0)} \mathrm{N}_{4,4}(\mathrm{u})+\frac{(2-\mathrm{u})}{(2-1)} \mathrm{N}_{5,4}(\mathrm{u})=\frac{\mathrm{u}}{2} \mathrm{~N}_{4,4}(\mathrm{u})+\frac{(2-\mathrm{u})}{(2-1)} \mathrm{N}_{5,4}(\mathrm{u})$

$\mathrm{N}_{5,5}(\mathrm{u})=\frac{(\mathrm{u}-1)}{(2-1)} \mathrm{N}_{5,4}(\mathrm{u})+\frac{(2-\mathrm{u})}{(2-2)} \mathrm{N}_{6,4}(\mathrm{u})=(\mathrm{u}-1) \mathrm{N}_{5,4}(\mathrm{u})$

After finding the equation for different orders, these equations are compensated with each other to get the basis function.

$1-\mathrm{N}_{0,5}(\mathrm{u})=(1-\mathrm{u}) \mathrm{N}_{1,4}(\mathrm{u})=(1-\mathrm{u})(1-\mathrm{u}) \mathrm{N}_{2,3}(\mathrm{u})=(1-\mathrm{u})(1-\mathrm{u})(1-\mathrm{u}) \mathrm{N}_{3,2}(\mathrm{u})=(1-\mathrm{u})(1-\mathrm{u})(1-\mathrm{u})(1-\mathrm{u}) \mathrm{N}_{4,1}(\mathrm{u})$

$\mathrm{N}_{0,5}(\mathrm{u})=\mathrm{u}^{4}-4 \mathrm{u}^{3}+6 \mathrm{u}^{2}-4 \mathrm{u}+1$ for $0 \leq \mathrm{u}<1$

2-The same procedure can be followed to get the other blending function as follow:

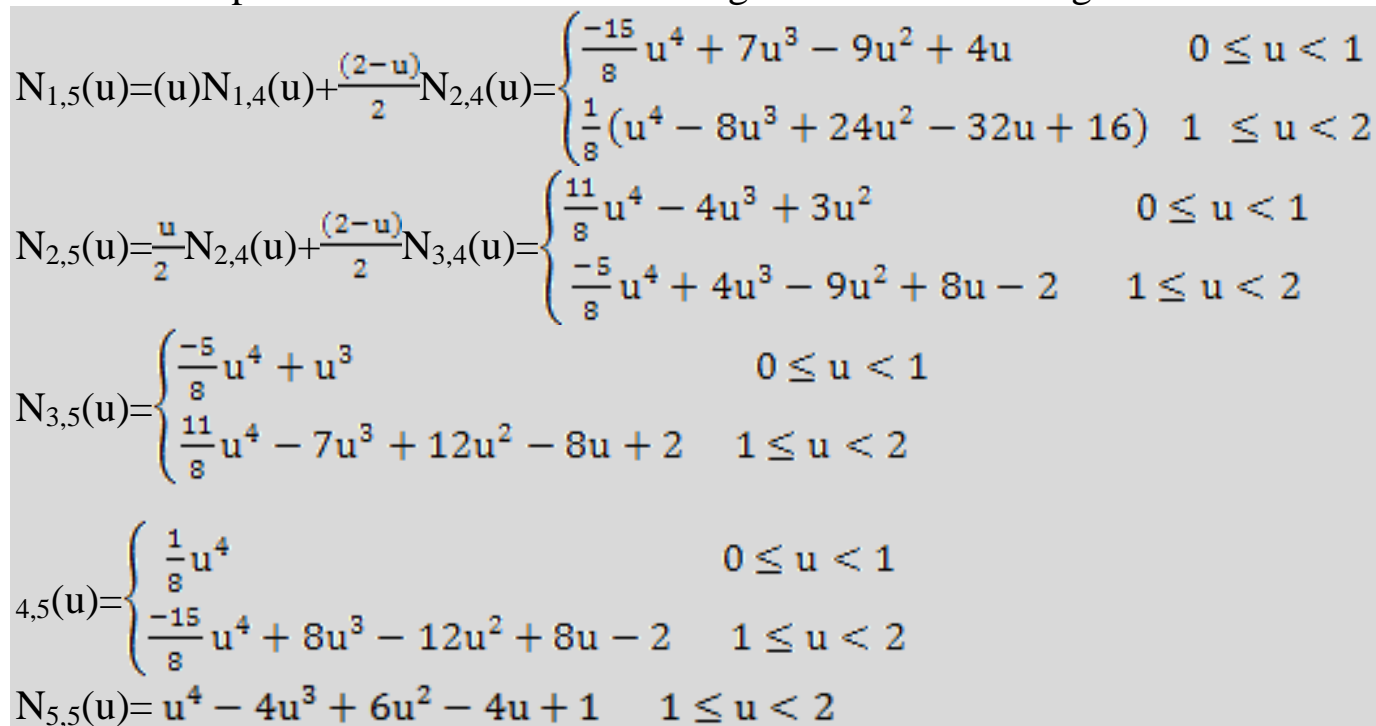

As a result of compensation these equations, two different basis functions will be produced. The matrix forms of these basis functions are: 
For $\mathrm{i}=1: \mathrm{P}_{1}(\mathrm{u})=\frac{1}{8}\left[\mathrm{u}^{4} \mathrm{u}^{3} \mathrm{u}^{2} \mathrm{u} 1\right]\left[\begin{array}{ccccc}8 & -15 & 11 & -5 & 1 \\ -32 & 56 & -32 & 8 & 0 \\ 48 & -72 & 24 & 0 & 0 \\ -32 & 32 & 0 & 0 & 0 \\ 8 & 0 & 0 & 0 & 0\end{array}\right]\left[\begin{array}{l}p_{0} \\ p_{1} \\ p_{2} \\ p_{3} \\ p_{4}\end{array}\right]$
For $\mathrm{i}=2: \mathrm{P}_{2}(\mathrm{u})=\frac{1}{8}\left[\mathrm{u}^{4} \mathrm{u}^{3} \mathrm{u}^{2} \mathrm{u} 1\right]\left[\begin{array}{ccccc}1 & -5 & 11 & -15 & 8 \\ -8 & 32 & -56 & 64 & -32 \\ 24 & -72 & 96 & -96 & 48 \\ -32 & 64 & -64 & 64 & -32 \\ 16 & -16 & 16 & -16 & 8\end{array}\right]\left[\begin{array}{l}p_{1} \\ p_{2} \\ p_{3} \\ p_{4} \\ p_{5}\end{array}\right]$

\section{Curve Model In Simulation Process}

The mathematical formulation of the B-spline technique in previous section have been implemented and integrated with MATLAB software (V.7) to generate the curve dependent on initial control points. Figure(2). represent the shape of open uniform B-spline curve was used in simulation process, this curve constructed by using $(\mathrm{n}=\mathrm{k}=5)$, which consists of two segments and six control points $\mathrm{P}_{0}(-112.5,21), \mathrm{P}_{1}(-67.5,11.5), \mathrm{P}_{2}(22.5,3.85), \mathrm{P}_{3}(22.5,3.85), \mathrm{P}_{4}(67.5,11.5)$, and $\mathrm{P}_{5}(112.5,21)$, five control points for each segment.

\section{MULTI-POINT FORMING PROCESS AND FINITE ELEMENT MODEL}

\section{The Forming Process Of MPF}

The general MPF process includes the following steps:

I-Calculate the height of punch elements according to the computer aided design model of desired parts on computer. Table 1 represents the coordinate of point located at center of pin in half die model taken from software .

II-The height of each pin is entered to ANSYS program to generate the same profile surface and to make simulation for the MPF.

\section{Materials}

In the numerical analysis, the material of sheet metal is aluminum alloy 1060, which is extensively applied in aircraft outer skin productions. The mechanical properties of Aluminum 1060 in experimental are elastic modulus of elasticity $\mathrm{E}=70 \mathrm{GPa}$, Poisson's ratio $v=0.33$, yield strength $\sigma \mathrm{y}=68.9 \mathrm{MPa}$, and tangent modulus $\mathrm{E}_{\mathrm{t}}=0.1 \mathrm{GPa}$.In this work two types of interpolator were simulated the first is lead which have the following mechanical properties: $\mathrm{E}=15 \mathrm{GPa}$, Poisson's ratio $v=0.45$, yield strength $\sigma y=20 \mathrm{MPa}$, and tangent modulus $\mathrm{E}_{\mathrm{t}}=10 \mathrm{MPa}$ [Ahmed 2014]. The second is Polyurethane which used as the material of elastic cushion in the present numerical analysis and which is more resistant to attack by oils and has better wear resistance than most other polymers. Polyurethane is an elastomer. Elastomers are the Mooney-Rivlin (2 parameters) hyper elastic material model which is used in numerical simulation. Mechanical properties of elastic cushion material are : $\mathrm{E}$ is (2.87) MPa, $v$ is (0.499)and Mooney-Rivlin Constants C1,C2 are (0.293) and (0.177) MPa [Mustafa 2013]. In the following analyses, the friction coefficient between the blank and rubber is(0.1) and between the rubber and pins is (0.2)[ Zhong-Yi 2009], and between the blank and tools is assumed as (0.1).

\section{Finite Element Discretization}

In this paper, a commercial FE code (ANSYS 11) is used to simulate the multi-point forming die operation .The blank modeled with (visco 106 element). The tool set (upper punches, lower punches , die , and blank holder) was modeled as rigid bodies. The contact interface between the die and the deformed material is represented by (contact element 172 and target 169). The blank dimensions are 
$(320 * 320 * 1) \mathrm{mm}^{3}$. The dimensions of the interpolator are $(240 * 240 * 4) \mathrm{mm}^{3}$. A MPD was created. Due to the symmetry, only one half of $2 \mathrm{D}$ model needed is be analyzed ,the profile of the final part geometry to be obtained is a B-spline curved plate. In the simulation, the effect of several parameters has been studied and discussed and these parameters are:

The Effect Of Hemispherical End Radius Of Punch Element: In MPF composed of $16^{*} 16$ punch element three kinds of the radii of the hemispherical end $(6.5,7,8) \mathrm{mm}$ were used. Figure(3). shows the von Misses stress distributed along length with these radii. The material used in simulation is aluminum with $1 \mathrm{~mm}$ thickness and attached by $5 \mathrm{KN}$ BHF. The numerical results of the von-Misses stress distribution along length with different radii are given in Figure(4), and from this figure, it can be concluded that the stress decreases with the increment of radius of punch end. Figure(5). presents the effect of different radii of hemispherical end of punch element on the thickness distribution. These results show that when the radius of hemispherical end is $6.5 \mathrm{~mm}$, the fluctuation in curve is evidence. When the radius of hemispherical end is $8 \mathrm{~mm}$, the curve changes steadily, and these illustrated dimple are smaller on formed part. From the observed result, it can be concluded that the larger end radius of punch element gives slighter dimples. When the punch radius increase the contact area will increase with reduce of curvature , and dimple will be slighter . The numerical results show that the larger hemispherical end radius should be selected to insure that the contact between the blank and punch element is good. concerning the effect of punch radius on shape error.

$\mathrm{E}_{\mathrm{rr}}=\sqrt{\frac{1}{n} \sum_{i=1}^{n}\left(y_{i}-y_{\mathrm{ti}}\right)^{2}}$

Where $\mathrm{n}$ is the number of sampling points, $\mathrm{y}_{\mathrm{i}}$ and $\mathrm{y}_{\mathrm{ti}}$ are the $\mathrm{y}$ coordinates at the ith sampling point on the formed part and desired part respectively, Figure(6). shows the effect of punch radii $(6.5,7,8)$ $\mathrm{mm}$ on shape aquracy. From this figure, the following features can be found:

1-The shape error distribution with $6.5 \mathrm{~mm}$ is larger than those of $(7,8) \mathrm{mm}$.

2-In the region near the edge of MPD, the shape error sharply increases and when the punch radius is $6.5 \mathrm{~mm}$ the average shape error is $(0.26 \mathrm{~mm})$.in the case of $(7,8) \mathrm{mm}$, the average shape error is $(0.18 \mathrm{~mm}),(0.17 \mathrm{~mm})$ respectively, so from these result it can be seen that the shape accuracy increases with increment of punch tip radius.

The Effect of Interpolator Material: The use of interpolator will improve the contact condition between the sheet and discrete die and it will suppress the dimple in MPF. But the interpolator may make discrepancy between the shape of deformed and desired part. To investigate the influence of interpolator material on the shape of work piece, numerical simulation with different interpolators (rubber and lead) on aluminum work pieces were carried out. The von Misses stresses distribution on the distance from center along the length of plate with (1) mm thickness and with(2mm) lead and rubber interpolator are shown in Figure(7) and Figure(8). From the relation between the von Misses stress and the distance from the center along the plate length with $(1 \mathrm{~mm})$ plate thicknesses ,it can be seen that the influence of rubber to reduce the stress on the part surface is greater than the influence the lead material. These results shown in Figure(9).

The Effect Of Elastic Caution Thickness: To investigate the effect of the interpolator thickness three values of thickness $(2,3,4) \mathrm{mm}$ for two types of interpolator (rubber and lead) were taken. Figure(10). to Figure(13) show von Misses distribution with 3 and $4 \mathrm{~mm}$ rubber and lead interpolator thickness from the center distance along the aluminum plate length with (1)mm thicknesses. Figure(14) and Figure(15). show the relation between von-Mises stress and the center distance along the sheet length with presence and absence the interpolator with different thicknesses, from this figure it can be seen that the stress distribution decreases with thick interpolator. The numerical results of the thickness distribution from the central distance along $1 \mathrm{~mm}$ aluminum with different rubber and lead thicknesses are shown in Figure(16). and Figure(17). ,from these figures it can be observed that to reduce the thickness change, a thick interpolator 
should be employed. The dimple effect decreases when the thickness variation is small and from Figure(18). it can be conclude that the best interpolator is the rubber and this interpolator must be uses in experimental work.

\section{Designing and Manufacturing Process}

The rig for multi-point forming process was composed of the upper multi-point die (UMPD) and the lower multi-point die (LMPD). Each multi-point die has the working arrays with (256) pins for each array, (16) rows and columns on both $x$ and $y$-direction. The forming area equal to $(242 \mathrm{~mm} *$ $242 \mathrm{~mm}$ ). The pins are displayed face to face, both on $x$ and $y$-direction .In this work, (256) pins for each array were selected for the following reasons:

1. The size of the place for the rig in the universal mechanical tests machine in University .

2. The cost of the materials and manufacturing to build the rig.

The LMPD was composed of three parts (the lower base, the lower plate contains the working array, and the die frame) are welded together .The UMPD was composed of three parts (the upper base , the upper plate and the blank holder) ,the blank holder consist of three parts (plate ,four shafts and four springs), the upper plate contains the working array and four holes to insert the $\mathrm{BH}$ shaft through it, this plate welded with the upper base and then the results parts connected with the blank holder ,the die frame dimensions are $(320 * 320 * 10) \mathrm{mm}^{3}$, and fillet with $(5 \mathrm{~mm})$ radius to ensure easy flow of sheet material into the die cavity, the length of horizontal edge is $(39 \mathrm{~mm})$, and the length of vertical edge is $(20 \mathrm{~mm})$, the outer dimensions of lower base are $(300 * 300 * 10) \mathrm{mm}^{3}$ and the inner dimensions are $(238 * 238 * 10) \mathrm{mm}^{3}$, the length of the edge is $(25 \mathrm{~mm})$ and the total height of the base is $(55 \mathrm{~mm})$, the lower and upper plates dimensions are $(300 * 300 * 10) \mathrm{mm}^{3}$ and $(318 * 318 * 10) \mathrm{mm}^{3}$ respectively and they have the working array which consist of 256 hole ,the diameter of the hole is $(8 \mathrm{~mm})$ and the distance between the centers of the holes is $(15 \mathrm{~mm})$.

The outer dimensions of the upper bases are $(270 * 270 * 10) \mathrm{mm}^{3}$ and the inner dimensions are $(240 * 240 * 10) \mathrm{mm}^{3}$, and the total height of the base is $(40 \mathrm{~mm})$, the outer dimensions of the plate are $(320 * 320 * 10) \mathrm{mm}^{3}$ and the inner dimensions are $(242 * 242 * 10) \mathrm{mm}^{3}$, also this plate contain four holes, the distance from the center to the plate edge is $16.5 \mathrm{~mm}$, the length and diameter of the shafts are (100 and 10) mm respectively, and finally the springs dimensions are listed in Table.2 .

Figure(19-a) shows the MPD parts before combination with pin matrix: The upper and lower parte each one has 256 holes are manufactured by using a vertical drill and the two plates and die frame are manufactured of iron metal, the lower base welded with lower plate and the two bases are manufactured of iron metal, the blank holder connected with the upper plate.Figure(19-b) Shows the lower MPD with pin matrix . Figure(19-c) shows the upper MPD with pin matrix.

\section{The Forming Process}

In the forming process, it is required to move the UMPD with $(27.85 \mathrm{~mm})$ displacement in $\mathrm{Y}$ direction to generate complete the full stroke for sheet forming. The blank is $320 * 320 * 1 \mathrm{~mm}^{3}$ aluminum 1060. The MPD during the forming process was pressed by using WDW model (100D3) with maximum load capacity $(100 \mathrm{KN})$. $(4 \mathrm{~mm})$ of rubber interpolator was used to suppress the dimple defect and the experimental results for the relation between the forming load and punch travel are shown in Figure(20). From this figure it can be seen that the starting forming load is (4 $\mathrm{KN}$ ) although there is no contact between upper die and lower die with the work piece. This value represents the force required to compress the four springs with the effective stiffness $\left(\mathrm{K}_{\mathrm{e}}=75 \mathrm{~N} / \mathrm{mm}\right)$ located in UMPD to generate the part of blank holder force and applied by the blank holder plate, also it can be seen clearly that the forming force depends on the contact state. During the initial stage the forming force is small because only a few of punches are in contact with sheet metal, and its force increase slowly. After the travel of punch reaches a value about the half of the travel distance, more and more punches get into contact with sheet and the forming force increases sharply. At the end of MPF process, the forming force reach to the maximum value. Experiment 
work showed that the suppression of dimpling in the sheet metal is easily accomplished by sandwiching the sheet blank between two polymer blankets as shown in Figure(21-a). The product was divided in to two parts by using a diamond saw to measure the product thickness. Micrometer and electronic digital caliper with accuracy of $(0.01 \mathrm{~mm})$ were used to measure the product thickness variation along $\mathrm{X}$ and Z-axis.(Figure22-b). shows the deformation results in half part of the same plate numerically and experimentally. Fig.23 shows the comparison between numerical and experimental thickness variation along the $\mathrm{X}$-axis and $\mathrm{Z}$-axis and the comparison results show the error percentage between the numerical and experimental work is $(5 \%)$.

\section{CONCLUSIONS}

1- The thickness variation, stress distribution, and dimple defect along the sheet metal without elastic cushion is greater than with elastic cushion.

2-The thickness variation, Von-Mises stress, and dimpling defect decrease with increase the elastic cushion thickness.

3-With the rubber interpolator the thickness variation ,Von-Mises stress, and dimpling defect smaller than with the lead interpolator.

4-When the punch tip radius increase the stress distributed uniformly along the sheet metal, also the thickness variation and dimpling defect decrease.

Table 1 Represent the coordinate of points located at center of pin in half die model

\begin{tabular}{|l|l|}
\hline $\mathrm{X}$ & $\mathrm{Y}$ \\
\hline 7.5 & 0 \\
\hline 22.5 & 1.37 \\
\hline 37.5 & 3.64 \\
\hline 52.5 & 6.83 \\
\hline 67.5 & 10.42 \\
\hline 82.5 & 14.06 \\
\hline 97.5 & 17.56 \\
\hline 112.5 & 20.85 \\
\hline
\end{tabular}

Table 2 Dimensions of the spring.

\begin{tabular}{|l|l|l|l|l|}
\hline Diameter & Width & Length & Number of turns & Stiffness(N/mm) \\
\hline 5 & 30 & 75 & 7 & 75 \\
\hline
\end{tabular}

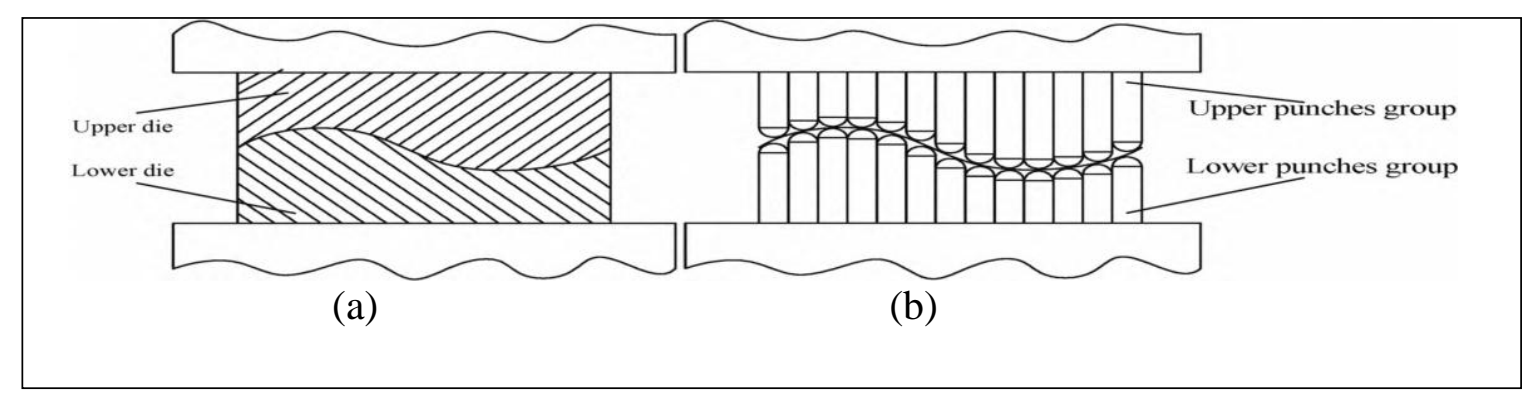

Fig.1 Schematic diagram of sheet metal forming:
a) Traditional sheet metal forming,
b) Multi-point forming of sheet metal 
NUMERICAL INVESTIGATION OF THE INFLUENCE OF PUNCH

\section{TIP RADIUS AND INTERPOLATOR TYPE IN MULTI-POINT FORMING}

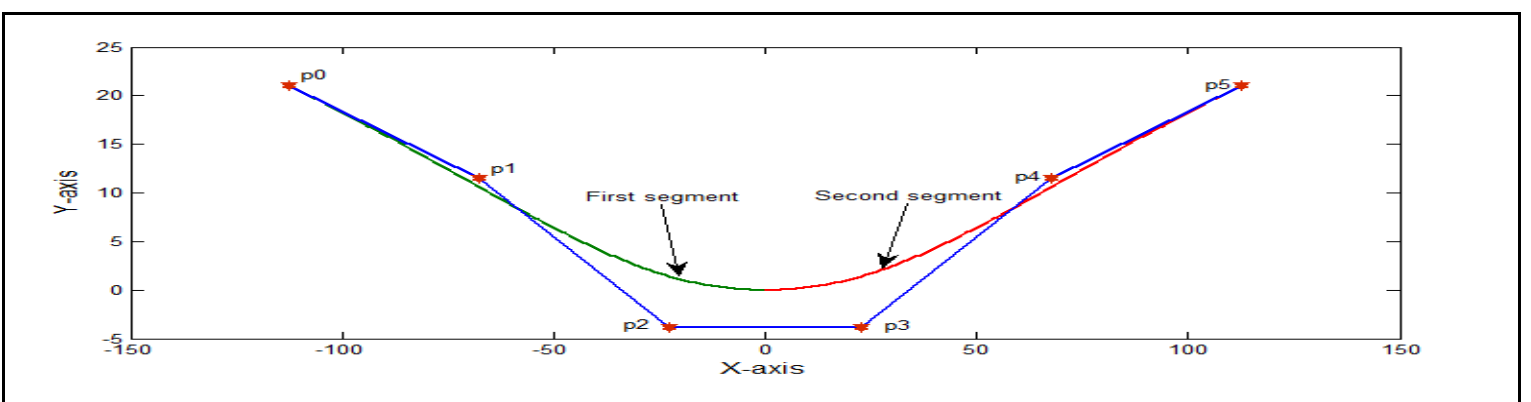

Fig.2 Represent the shape of the curve

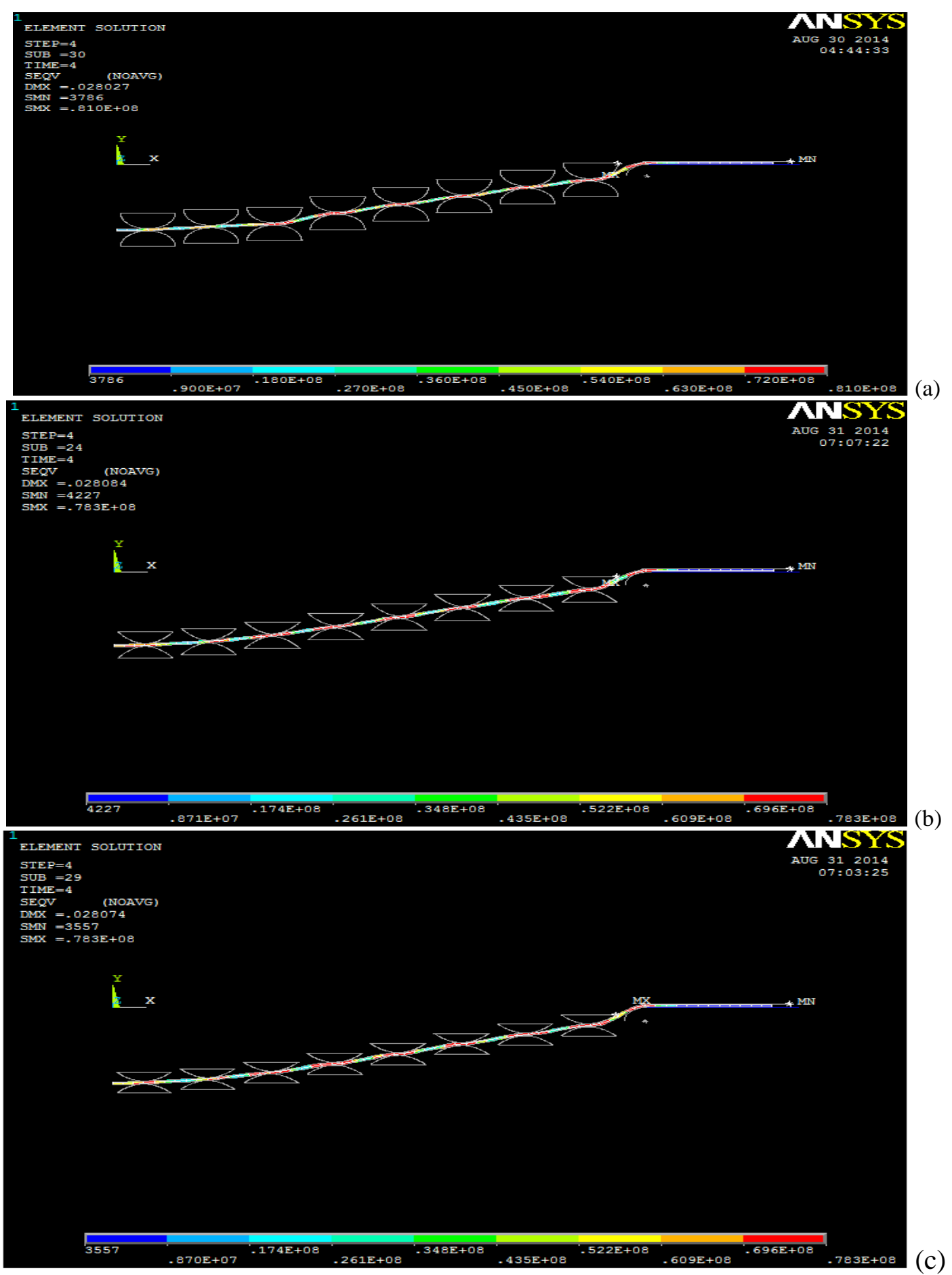

Fig.3Von-Mises stress distribution along $1 \mathrm{~mm} \mathrm{Al} \mathrm{plate} \mathrm{with} \mathrm{:a)6.5,} \mathrm{b)7,} \mathrm{and} \mathrm{c)} 8 \mathrm{~mm}$ pin tip radius. 


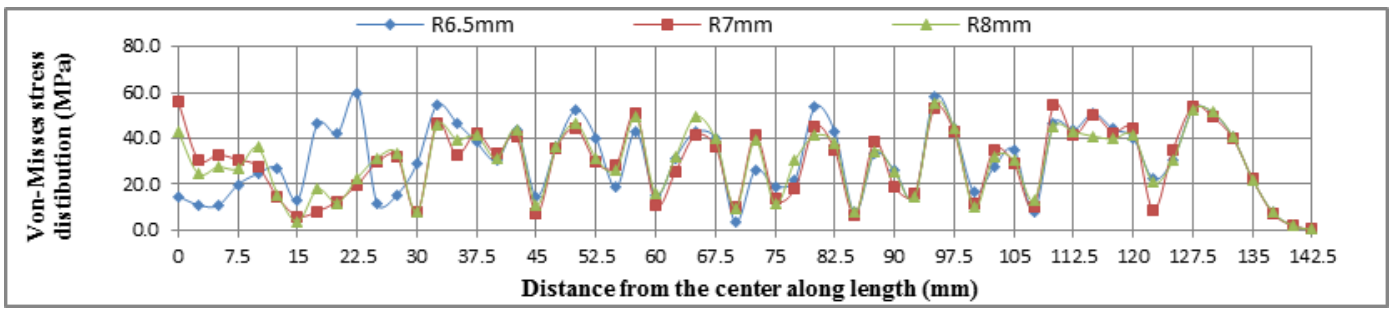

Fig. 4Von-Misses stress distribution along the Al sheet metal formed by different punch tip radius.

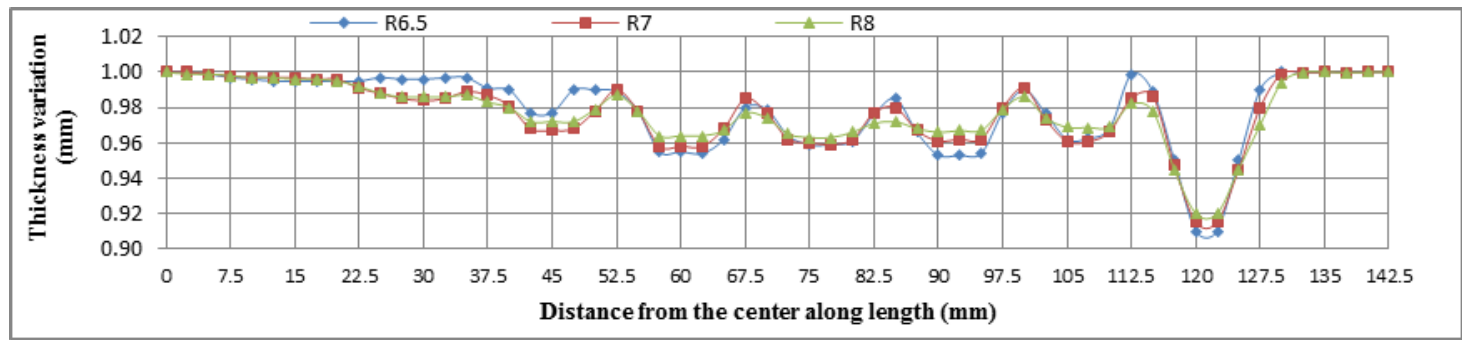

Fig.5 Thickness variation along the $1 \mathrm{~mm} \mathrm{Al}$ plate by different punch tip radius.

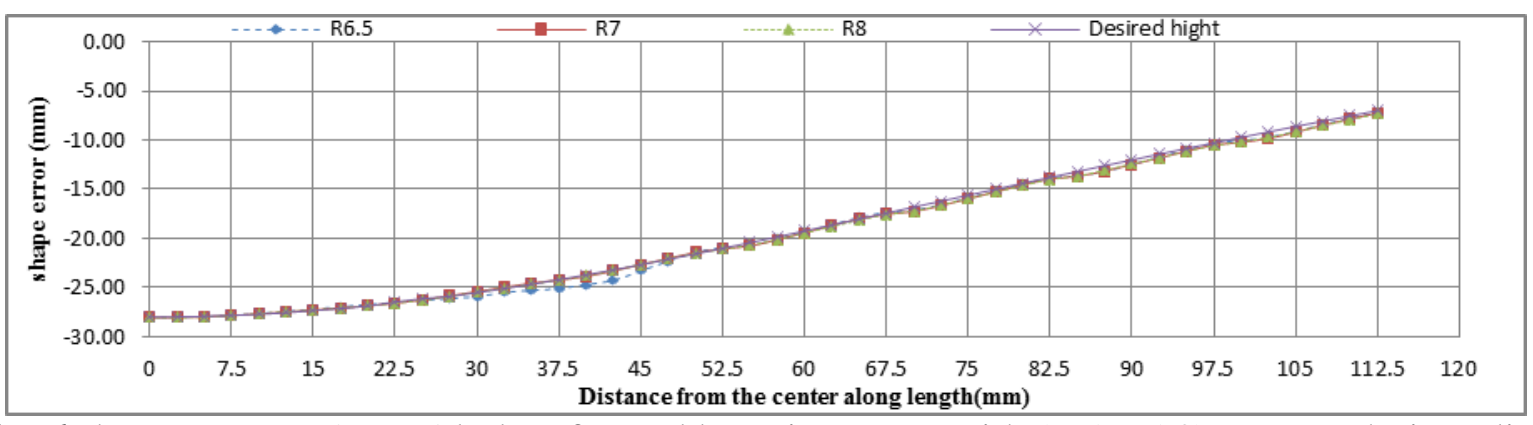

Fig. 6 shape error on $1 \mathrm{~mm} \mathrm{Al} \mathrm{plate} \mathrm{formed} \mathrm{by} \mathrm{using} \mathrm{MPD} \mathrm{with}(6.5,7.5,8) \mathrm{mm}$ punch tip radius.

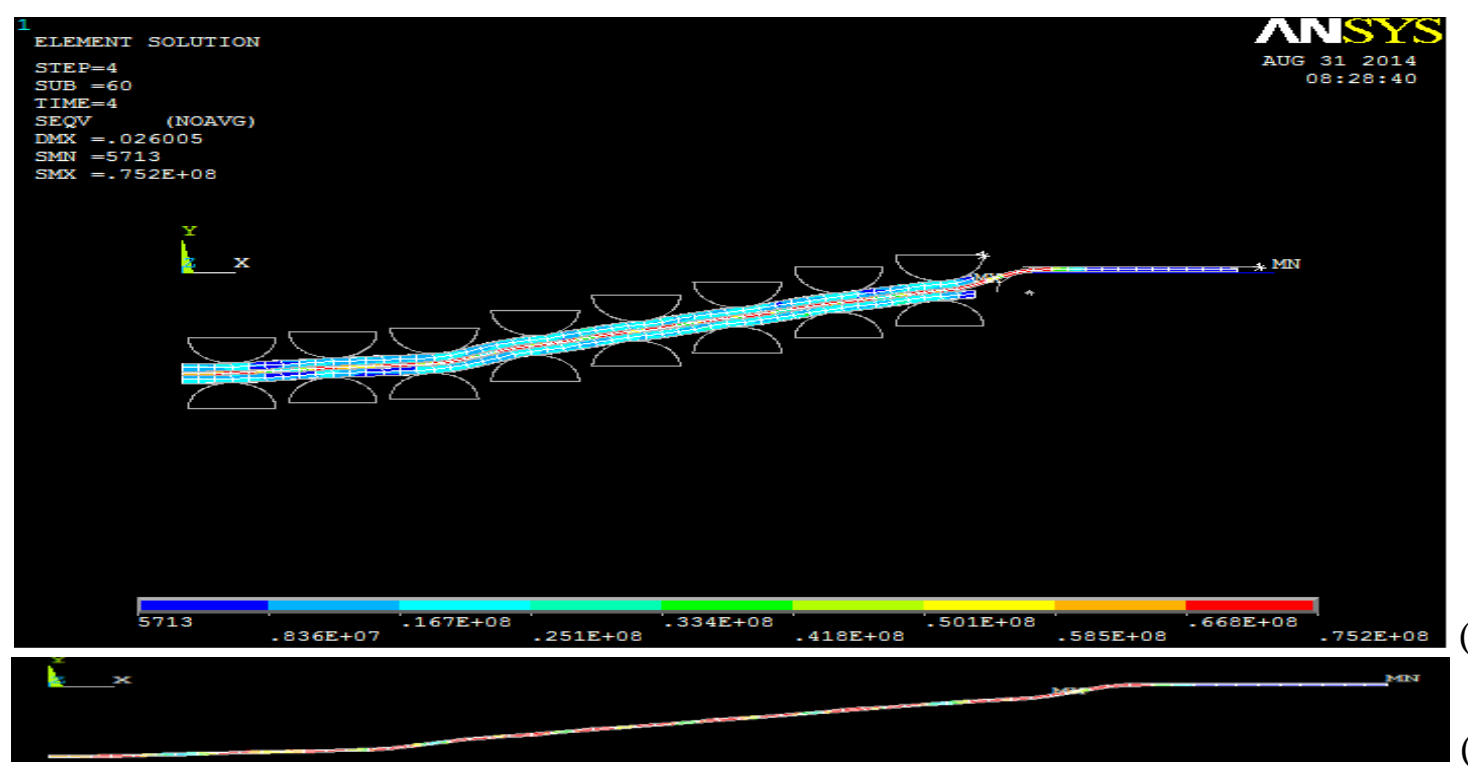

Fig.7 Von-Mises stress distribution along length of $1 \mathrm{~mm} \mathrm{Al}$ plate with $2 \mathrm{~mm}$ lead interpolator : a-half die model and b-sheet metal only. 


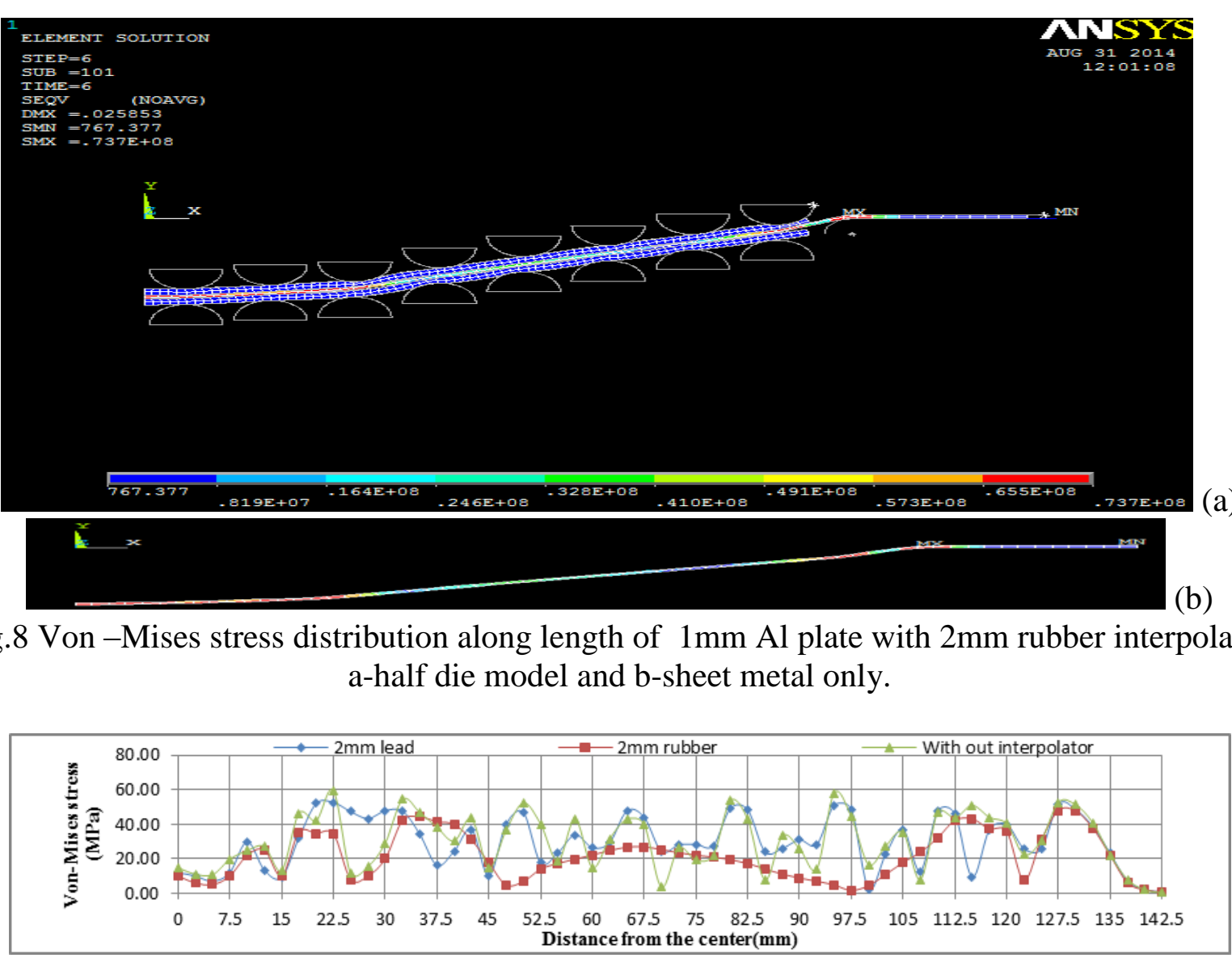

Fig. 9 Von -Mises stress distribution along $1 \mathrm{~mm}$ Al plate with $(2 \mathrm{~mm})$ lead and rubber interpolator.

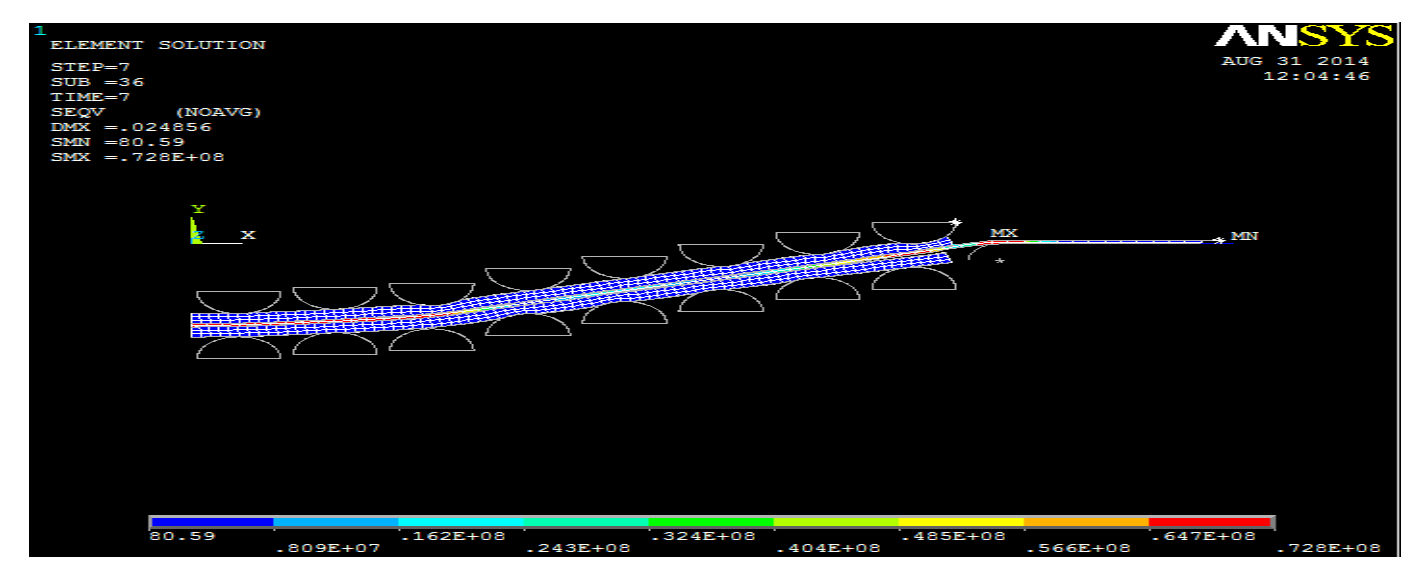

Fig.10Von-Misses stress distribution along length of $1 \mathrm{~mm} \mathrm{Al}$ plate with $3 \mathrm{~mm}$ rubber interpolator.

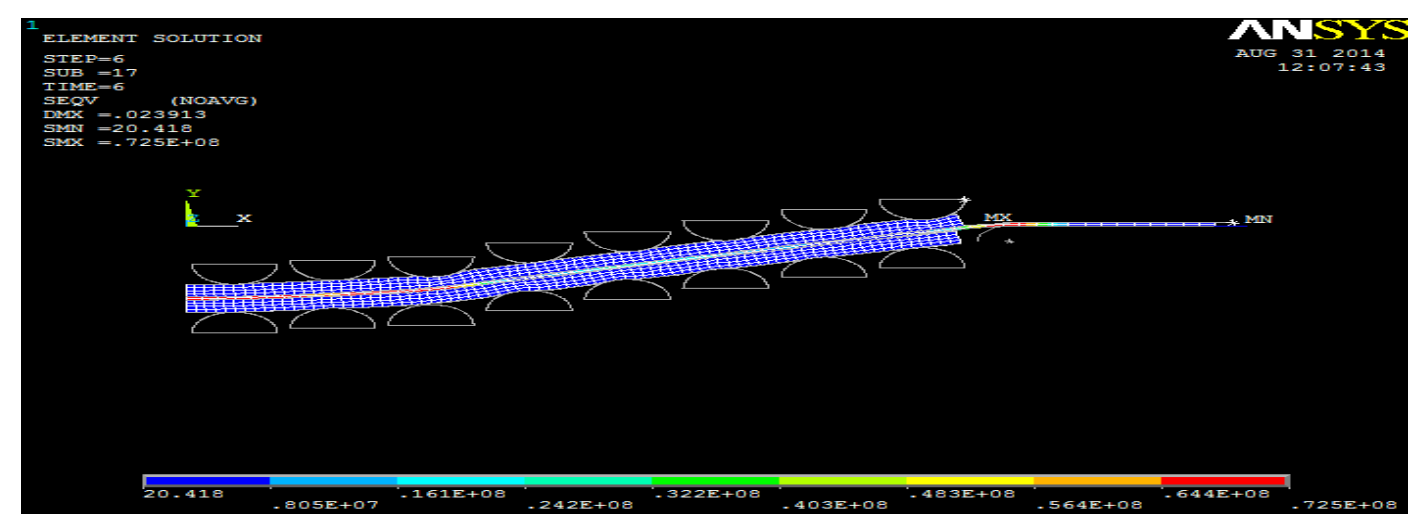

Fig.11Von-Misses stress distribution along length of $1 \mathrm{~mm} \mathrm{Al}$ plate with $4 \mathrm{~mm}$ rubber interpolator. 


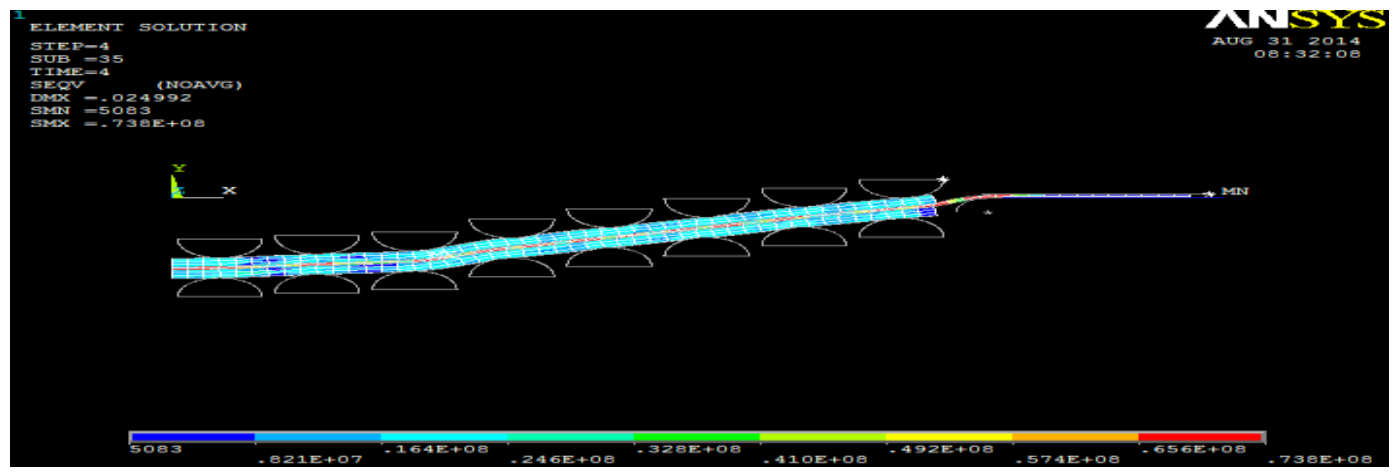

Fig.12 Von -Mises stress distribution along length of $1 \mathrm{~mm}$ Al plate with 3mm lead interpolator.

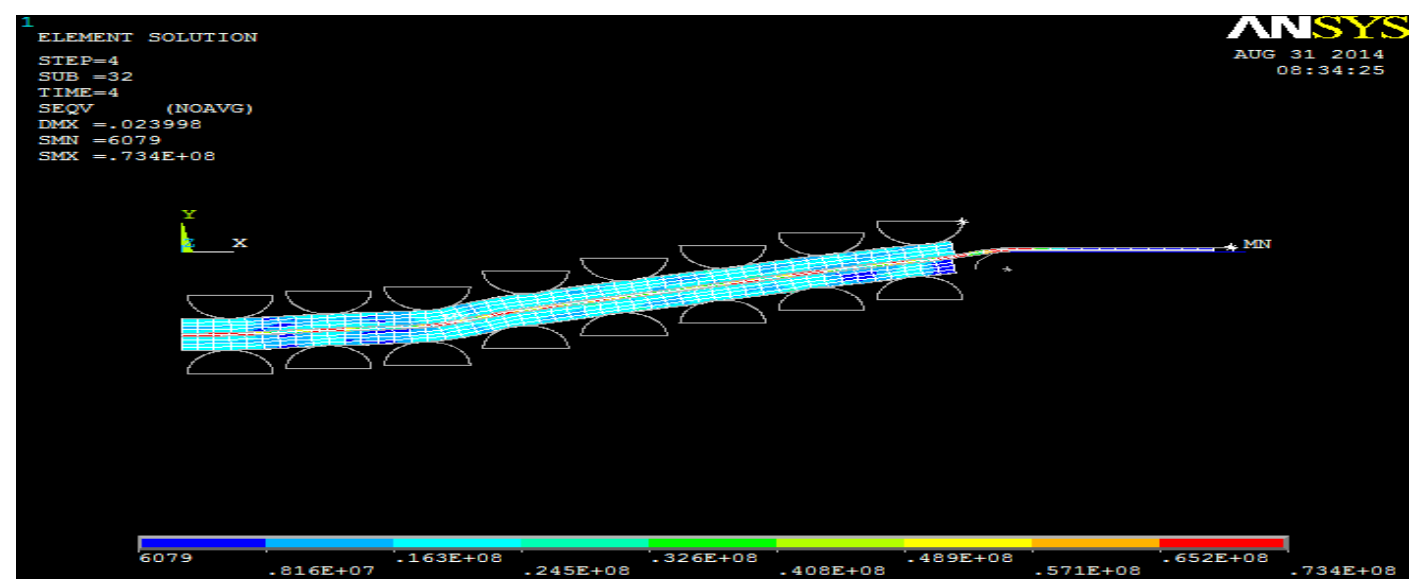

Fig.13Von -Mises stress distribution along length of $1 \mathrm{~mm}$ Al plate with 4mm lead interpolator.

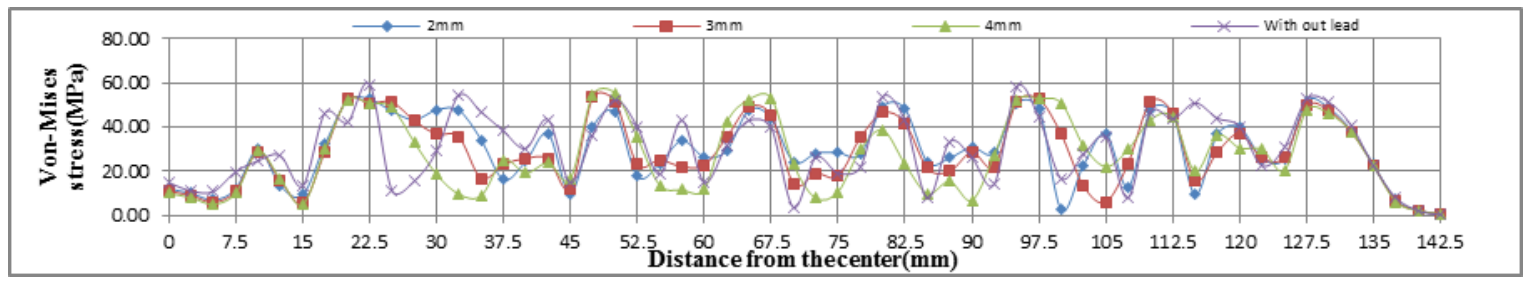

Fig.14 Von-Mises stress distribution along $1 \mathrm{~mm} \mathrm{Al} \mathrm{with} \mathrm{different} \mathrm{lead} \mathrm{thickness.}$

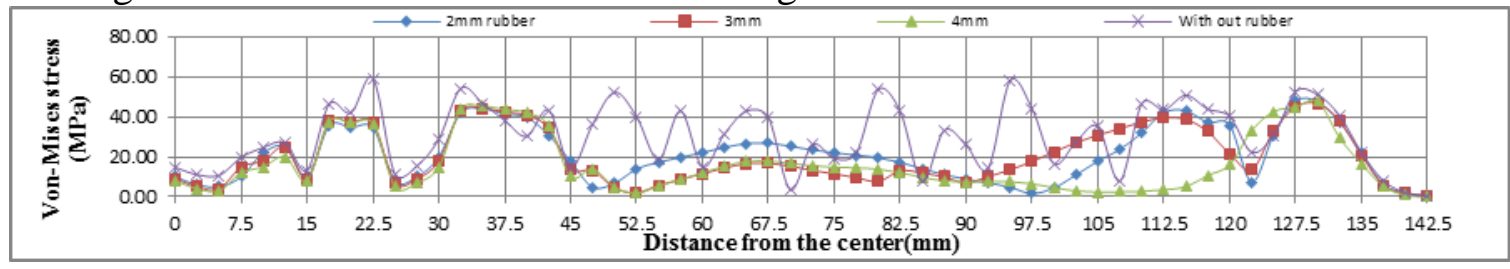

Fig.15 Von-Mises stress distribution along $1 \mathrm{~mm} \mathrm{Al} \mathrm{with} \mathrm{different} \mathrm{rubber} \mathrm{thickness.}$

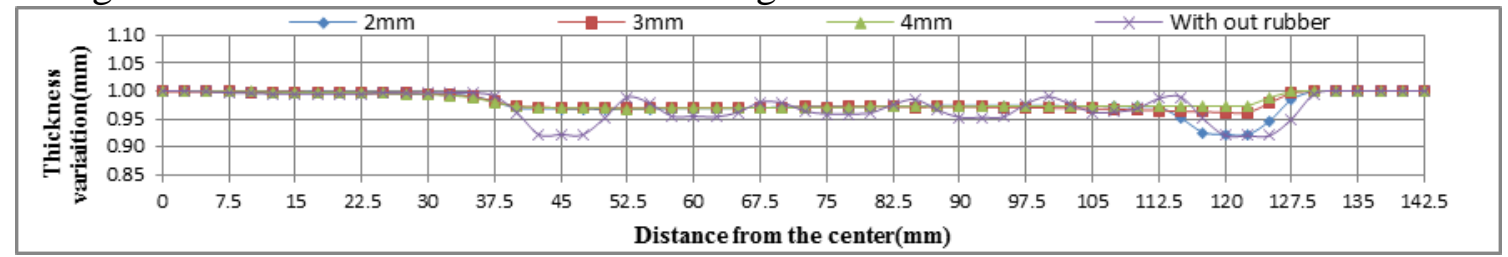

Fig.16 Thickness variation along $1 \mathrm{~mm} \mathrm{Al}$ with different rubber thickness.

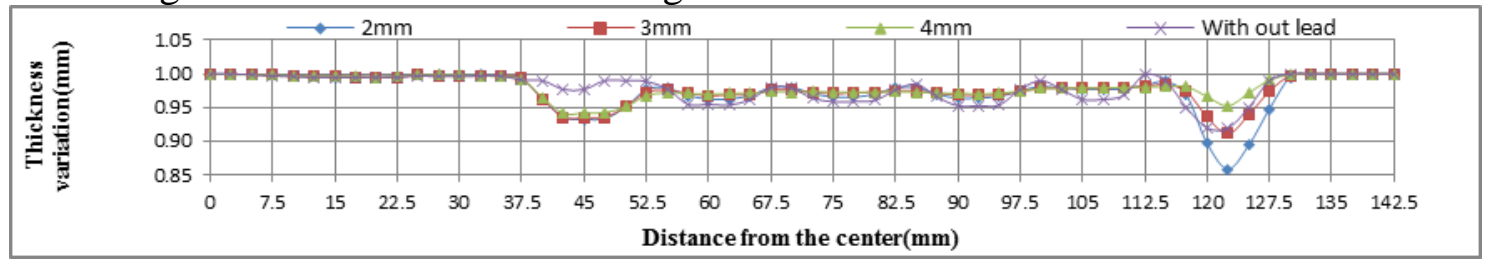

Fig.17 Thickness variation along $1 \mathrm{~mm} \mathrm{Al} \mathrm{with} \mathrm{different} \mathrm{lead} \mathrm{thickness.}$ 


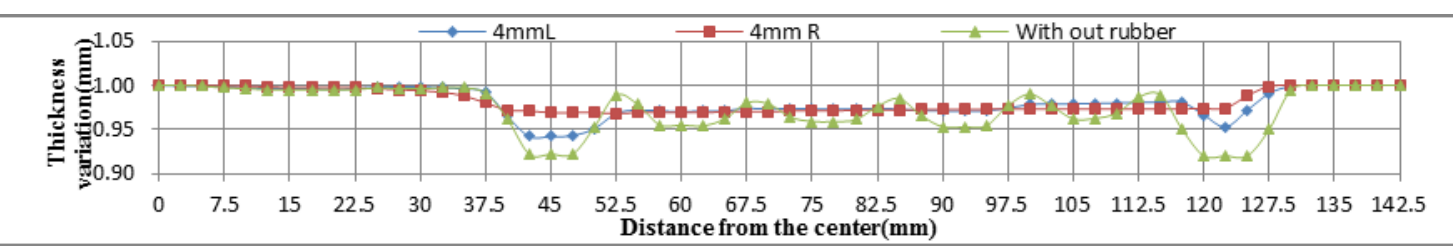

Fig. 18 The thickness variation along $1 \mathrm{~mm} \mathrm{Al}$ plate with $4 \mathrm{~mm}$ and without interpolator.
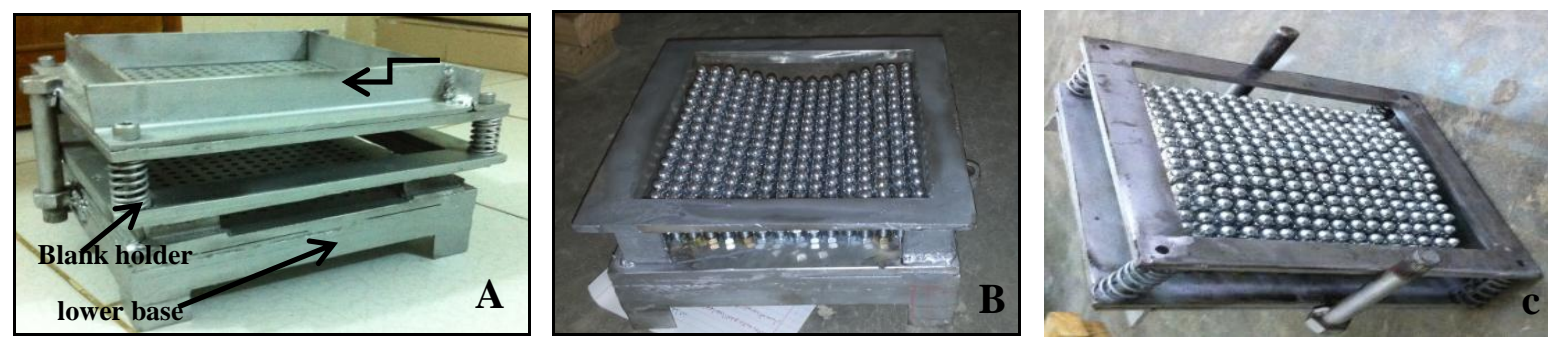

Fig.19. Assembled die.

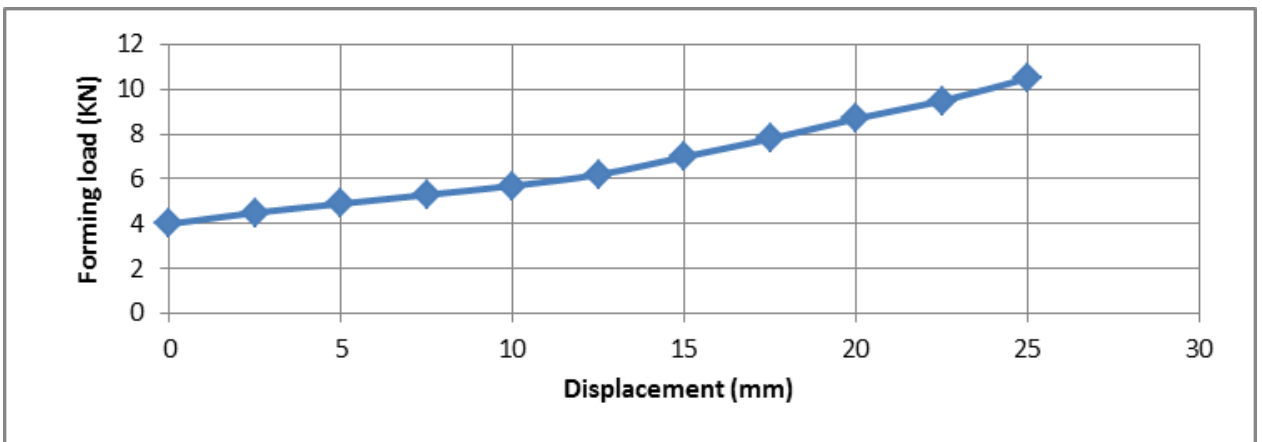

Fig.20 Forming load with 4mm rubber interpolator versus displacement.

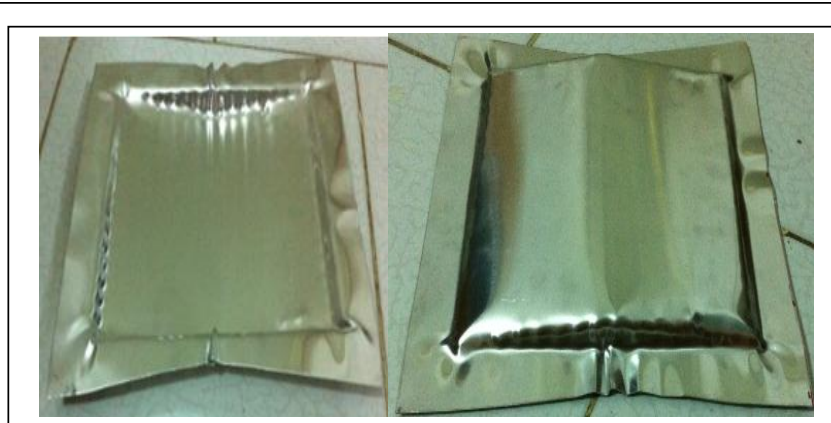

(A)

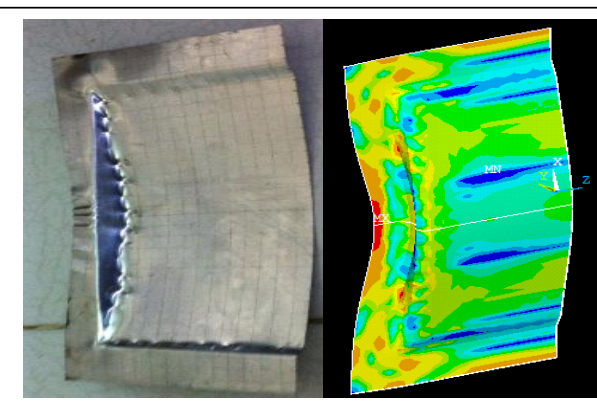

(B)

Fig .21 Formed sheet with using 4mm rubber elastic cushion:(A) top and bottom of all product experimentally, and (B) half product experimentally and numerically .

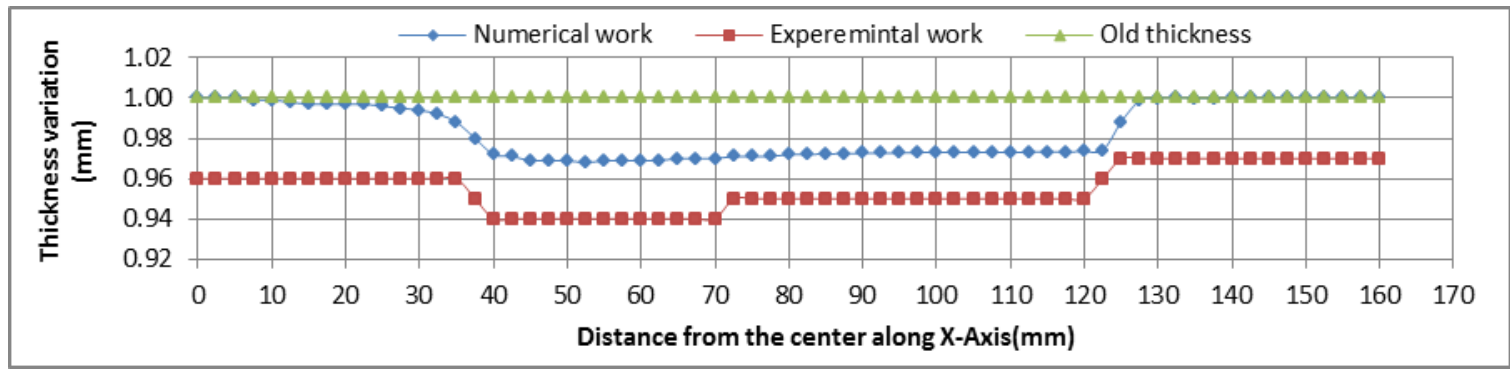

Fig.22 Thickness variation along $\mathrm{X}$-axis. 


\section{REFERENCE}

Ahmed W.H.," Theoretical and Experimental Appraisal of Three Dimensional Different Symmetrical Shaped Sections Extrusion Process", M.Sc. Thesis, University of Babylon, Iraq,(2014).

Cekan P., Paunoiu V., Gavan E. and Nicoara D., " Numerical Simulations in Reconfigurable Multipoint Forming ", Proceedings of the $11^{\text {th }}$ ESAFORM Conference on Material Forming, Lyon (France), pp. 23-25 April (2008).

Fredrik A.,"Bezier and B-spline Technology" ,June (2003).

Li M.Z., Cai Z.Y., Sui Z. and Yan Q.G., "Multi-point Forming Technology For Sheet Metal", Journal of Material Processing Technology, vol.129, pp.333-338,(2002).

Michael E. M. “Geometric Modeling” John Wiley and sons Inc, October (1996).

Mustafa A. A., "Computer Aided Design and Analysis of Reconfigurable Discrete Dies for Sheet Metal Forming”, M.Sc. Thesis, University of Babylon, Iraq,(2013).

Q. Zhang , Z.R. Wang and T.A. Dean," Multi-point sandwich forming of a spherical sector with tool-shape compensation"Journal of Materials Processing Technology, (2007).

Seong-chan H., Young-Ho S., Tae-Wan K. and Beom-Soo K."A Study on Thick Plate Forming using Flexible Forming process and Its Application to a Simply Curved Plate", Int J Adv Manuf Technol Vol. 51,pp.103-115, (2010).

Shaohui W., Zhongyi C., and Mingzhe L., "Numerical Investigation of the Influence of Punch Element in Multi-Point Stretch Forming Process" Int J Adv Manuf Technol, Vol.49, pp.475-483,(2010).

Tan F.,Li M.,Cai Z.,and Li X.," Formability analysis on the process of multi-point forming for titanium alloy retiary sheet", Int J Adv Manuf Technol ,(2009).

Wang L.,and Li L.," Computer Simulation of Thick Plate Multi-Point Forming Process", International Conference On Computer Design And Appliations,(2010).

Xi-Di C., Zhong-Yi C., and Ming-Zhe L.,"Digitized die forming system for sheet metal and springback minimizing Technique" Int J Adv Manuf Technol ,vol.28,pp. 1089-1096, (2006).

Zhong-Yi C., Shao-Hui W., Xu-Dong X.,and Ming-Zhe L. "Numerical simulation for the multi-point stretch forming process of sheet metal",journal of materials processing technology,vol. 209 ,pp.396-407,(2009). 